\title{
Methicillin-resistant Staphylococcus aureus in Human Milk
}

\author{
FR Novak/*/+, JAG Almeida*, MB Warnken**, BT Ferreira-Carvalho, \\ AN Hagler
}

\begin{abstract}
Instituto de Microbiologia Professor Paulo de Góes, Universidade Federal do Rio de Janeiro, CCS, Bloco I, Cidade Universitária, Ilha do Fundão, 21949-900 Rio de Janeiro, RJ, Brasil *Banco de Leite Humano, Instituto Fernandes Figueira-Fiocruz, Av. Rui Barbosa 716, 22250-020 Rio de Janeiro, RJ, Brasil **Instituto Nacional de Controle de Qualidade em Saúde- Fiocruz, Av. Brasil 4365, 21045-900 Rio de Janeiro, RJ, Brasil
\end{abstract}

We collected and analyzed 500 samples of human milk, from five Brazilian cities (100 from each) to detect methicillin-resistant strains of Staphylococcus aureus (MRSA) producing enterotoxins. We found 57 strains of MRSA, and the mecA gene, responsible for resistance, was detected in all of them using a specific molecular probe. We examined 40 strains for the presence of four enterotoxins, after selecting a subset that included all strains from each region, except for the largest sample, from which 10 were randomly selected. Among these two presented enterotoxin $B$, and growth in human colostrum and trypicase soy broth. After 5 h of incubation at $37^{\circ} \mathrm{C}$, population sizes were already higher than $9.4 \times 10^{5}$ $U F C / m l$ and enterotoxin was released into culture medium and colostrum. Our results stress the importance of hygiene, sanitary measures, and appropriate preservation conditions to avoid the proliferation of $\mathrm{S}$. aureus in human milk.

Key words: human milk methicillin-resistant - Staphylococcus aureus - enterotoxin - Brazil

In recent years, Staphylococcus aureus has emerged as one of the most important human pathogens in community and hospital settings (Kloos \& Bannerman 1995). Community infections by methicillin-resistant $S$. aureus (MRSA) strains were reported as early as 1981 (Layton et al. 1995). Nettleman et al. (1991) reported that $50 \%$ of MRSA strains isolated from Iowa City Medical Center (USA) originated from the community. Among these, $33 \%$ originated from inpatients in homes for the aged, $9 \%$ in patients transferred from other hospitals, and $58 \%$ were from patients arriving at the Center directly from home (Nettleman et al. 1991). In another study, involving five tertiary care hospitals in Canada, over the 1990-1992 period, $63 \%$ of the isolates had a community origin, and $81 \%$ were from local residents, referred to the community hospitals. The authors of the study suggested that the indiscriminate use of antibiotics on an empirical basis promotes the transmission and emergence of these organisms (Embil et al. 1994). In large university hospitals of the United States, the frequency of MRSA among $S$. aureus isolates from hospital infections has increased from $8 \%$ in 1986 to $40 \%$ in 1992 (Boyce et al. 1994).

\footnotetext{
$\overline{{ }^{+} \text {Corresponding author. Fax: }}+55-21-553.9662$. E-mail: novak@iff.fiocruz.br

Received 15 April 1999

Accepted 20 October 1999
}

Asymptomatic carriers play an important role in the maintenance and spread of these microorganisms, especially when the carriers have professional activities related to public health (Soares et al. 1997). The natural habitat of $S$. aureus is the body surface of mammals (Williams 1963), which accounts for its widespread presence in nature, its transmission to foodstuffs by asymptomatic carriers, and in animals, particularly cattle (Maschoshvili et al. 1991).

The presence of $S$. aureus in samples of human milk (HM) can be accounted for by secondary contamination from skin, breasts and the nasal cavity of milk donors and health care professionals, or alternatively, to unsatisfactory conditions of the utensils (Almeida et al. 1998). Pereira et al. (1995) demonstrated the presence of these microorganisms in 19 samples of HM, 9 of which were free of mastitis symptoms, while the remaining 10 had mastitis. In such samples, $S$. aureus counts ranged from $10^{2}$ to $10^{4} \mathrm{CFU} / \mathrm{ml}$ (Pereira et al. 1995).

Furthermore, inadequate handling of milk can contribute to the increase in staphylococcal numbers up to the moment of pasteurization (Brasil 1998), allowing for the production of thermostable toxins, which resist temperatures as high as $100^{\circ} \mathrm{C}$ for $30 \mathrm{~min}$. Pasteurized milk, which may be free of microorganisms, but not of enterotoxins (Maschohvili et al. 1991), can be given to premature babies, which are highly dependent on it for survival (Almeida et al. 1998). In the study referred above, with mastitis-afflicted and mastitis-free 
women from Brazil, Pereira et al. (1995) identified enterotoxin-producing strains in four samples from mastitis patients, as well as in four samples from mastitis-free women, with the help of the Optimum-Sensitivity-Plate (OSP) method. In addition, they identified two additional enterotoxinproducing strains with the help of the more sensitive Reversed Passive Latex Agglutination (RPLA) technique (Pereira et al. 1995).

Enterotoxins are among the extracellular proteins made by $S$. aureus that play a major role in the pathogenesis of staphylococcal disease (ICMSF 1978). They are classified in five large serological groups, termed A to E (Lebeau et al. 1994). These toxins present, in addition to their well-known emetic actions, the ability to bind to Class II molecules coded by the major histocompatibility complex, and to act as superantigens triggering polyclonal responses in target $\mathrm{T}$ lymphocytes, and resulting in large-scale secretion of cytokines, including tumor necrosis factor (TNF) and several interleukins (Bethey \& Harries 1994).

The goal of this study was to evaluate the frequency of enterotoxin-producing strains of MRSA in samples of HM, as well as their ability to produce enterotoxin in human colostrum.

\section{MATERIALS AND METHODS}

Sample collection - Samples of HM were obtained in five Brazilian cities, from 500 different registered and instructed regular donors, in the following HM banks: "Banco de Leite da Maternidade Januário Cicco", in Natal, State of Rio Grande do Norte; "Banco de Leite da Maternidade Escola Assis Chateaubriant", in Fortaleza, State of Ceará; "Banco de Leite do Instituto Fernandes Figueira", Rio de Janeiro, State of Rio de Janeiro; "Banco de Leite da Universidade de Brasília", Brasília, Federal District; and "Banco de Leite da Universidade Estadual do Paraná", Londrina, State of Paraná. Approximately $5 \mathrm{ml}$ of milk from the donated flasks were collected under aseptic conditions and transported frozen, by airplane, to Rio de Janeiro where the microbiological analyses were carried out.

Staphylococcus aureus counts - We inoculated $0.1 \mathrm{ml}$ of HM samples, in duplicate, at the appropriate dilutions, on Baird-Parker Agar, and incubated at $35 \pm 1{ }^{\circ} \mathrm{C}$ for $24-48 \mathrm{~h}$ before colony counting. Colonies were black, punctiform, surrounded by a white opaque halo, and with a transparent external layer (Speck 1996).

Isolation of methicillin-resistant S. aureus - We added $0.5 \mathrm{ml}$ of milk to $5 \mathrm{ml}$ of tripticase soy broth (TSB, Difco), with $\mathrm{NaCl} 7.5 \%$ and $10 \mu \mathrm{g} / \mathrm{ml}$ methicillin (Sigma), and incubation was carried out at $36 \pm 1^{\circ} \mathrm{C}$ for $24-48 \mathrm{~h}$. Samples that presented growth were inoculated on trypticase soy agar (TSA, Difco) and incubated at $35 \pm 1{ }^{\circ} \mathrm{C}$ for $24 \mathrm{~h}$. After growth, five colonies with morphology typical of Staphylococcus were inoculated in TSB. Cultures were incubated at $35 \pm 1{ }^{\circ} \mathrm{C}$ for $18 \mathrm{~h}$, under vigorous stirring and used for detection of MRSA, by assessing resistance to $25 \mu \mathrm{g} / \mathrm{ml}$ of methicillin, which was used to isolate pure cultures. Strains that were positive for mannitol, Gram staining, catalase, coagulase and thermonuclease were classified as $S$. aureus and kept frozen at $-80^{\circ} \mathrm{C}$, in TSB with glycerol at a $10 \%$ final concentration.

Detection of mecA genes - Hybridization with a molecular probe specific for the mecA gene, which accounts for methicillin-resistance, was carried out by the dot-blot method. The preparation of bacterial DNA and of the mecA probe, as well as the hybridization technique were those described in Soares et al. (1997).

Enterotoxin detection - Assays for enterotoxins $\mathrm{A}, \mathrm{B}, \mathrm{C}$ and $\mathrm{D}$ were carried out with a SETRPLA TD900 kit (Difco). Fourty of the 57 MRSA strains were assayed. These included all the MRSA isolates from four cities and ten from Natal. Technical conditions recommended by the manufacturer were used for running the assays.

Analysis of microbial growth - Two different enterotoxin B-producing S. aureus strains (066 and 255) were inoculated in duplicate, into $40 \mathrm{ml}$ of TSB or into $40 \mathrm{ml}$ fresh human colostrum. Enterotoxin-producing strains were previously activated in $2 \mathrm{ml}$ of TSB, incubated at $37^{\circ} \mathrm{C}$ for $24 \mathrm{~h}$, centrifuged at $800 \mathrm{x} \mathrm{g}$ under refrigeration at $4^{\circ} \mathrm{C}$ for 5 min and washed with TSB three times to remove preformed toxin. The number of microorganisms in the inoculum was estimated by turbidimetry at $560 \mathrm{~nm}$, and diluted to approximately $5,0 \times 10^{2}$ CFU, in $1 \mathrm{ml}$ of human colostrum or TSB. Growth was evaluated in screw-cap flasks incubated at $37^{\circ} \mathrm{C}$, to simulate the summer temperatures in Rio de Janeiro. and population densities were determined at $0,1,2,3,4,5,8,12$ and $24 \mathrm{~h}$ by colony counts on Baird-Parker Agar, as described above.

\section{RESULTS}

Isolation of S. aureus from HM samples - A total of 171 strains of $S$. aureus were isolated from the $500 \mathrm{HM}$ samples, with the following distribution: Natal, 52/100; Fortaleza, 38/100; Brasília, 23/ 100; Rio de Janeiro, 29/100 and Londrina, 29/100.

Determination of methicillin-resistance - A total of 57 S. aureus strains showing resistance to 25 $\mu \mathrm{g}$ of methicillin $/ \mathrm{ml}$ were isolated from the 500 HM samples; and had the following distribution: Natal, 27/100; Fortaleza, 10/100; Brasília, 6/100; Rio de Janeiro, 8/100 and Londrina, 6/100. 
Detection of the mecA gene - The presence of the methicilin-resistance gene was confirmed in all methicilin-resistant cultures with a specific mecA gene probe (Fig. 1).

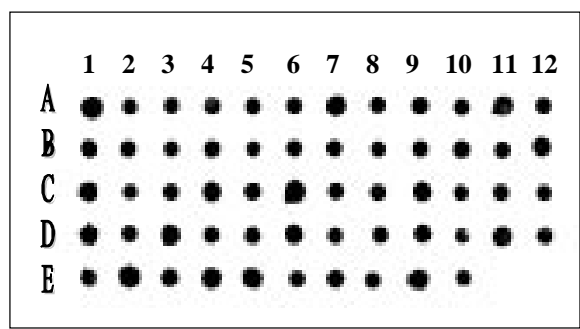

A1 - Positive control (Col) A2-A9 - Rio de Janeiro A10-B3 - Londrina B4-B9 - Brasília B10-C7 - Fortaleza C8-E10 - Natal
Fig. 1: Dot-blot hybridization of Staphylococcus aureus chromosome DNA with a specific mecA probe. Positive control, methicillin resistant $S$. aureus strain designated as $\mathrm{Col}$ (Soares et al. 1997).

Counting of $S$. aureus in samples containing methicilin-resistant strains - Seventy two percent of the 57 MRSA strains had counts in the range of $10^{2}-10^{3}$ CFU/ml (Fig. 2)

Enterotoxin-production - Two EEB-producing strains were detected, among the 40 methicillinresistant strains assayed with the SET-RPLA kit.

Growth curves of S. aureus strains in HM Bacterial growth in human colostrum was slower (generation time $42 \mathrm{~min}$ ) during the initial $5 \mathrm{~h}$ of culture, than that observed in culture medium (generation time 33 min; Fig. 3). After this period, microorganisms inoculated in colostrum presented an increased growth rate, comparable to that observed in culture medium, but did not reach the same final density. After $5 \mathrm{~h}$ incubation at $36 \pm 1^{\circ} \mathrm{C}$, the population size was seen to increase from $5 \times 10^{2}$ $\mathrm{CFU} / \mathrm{ml}$ to $9.4 \times 10^{5}$. Enterotoxin production in both culture media was observed for both of the EEB-producing strains.

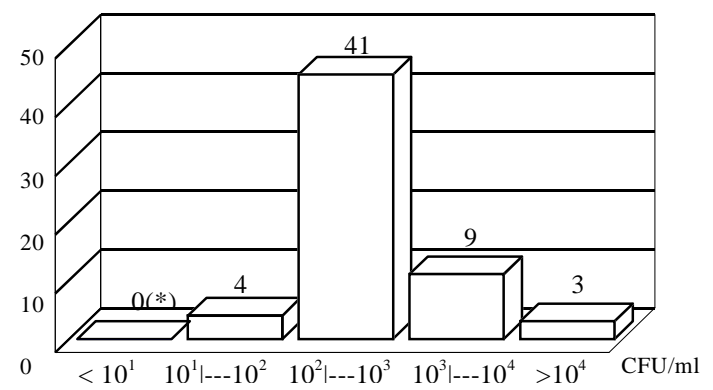

$(*)$ below the sensitivity of the assay.

Fig. 2: colony forming units per mililiter detected in 57 human milk presenting methicillin resistant Staphylococcus aureus contamination.

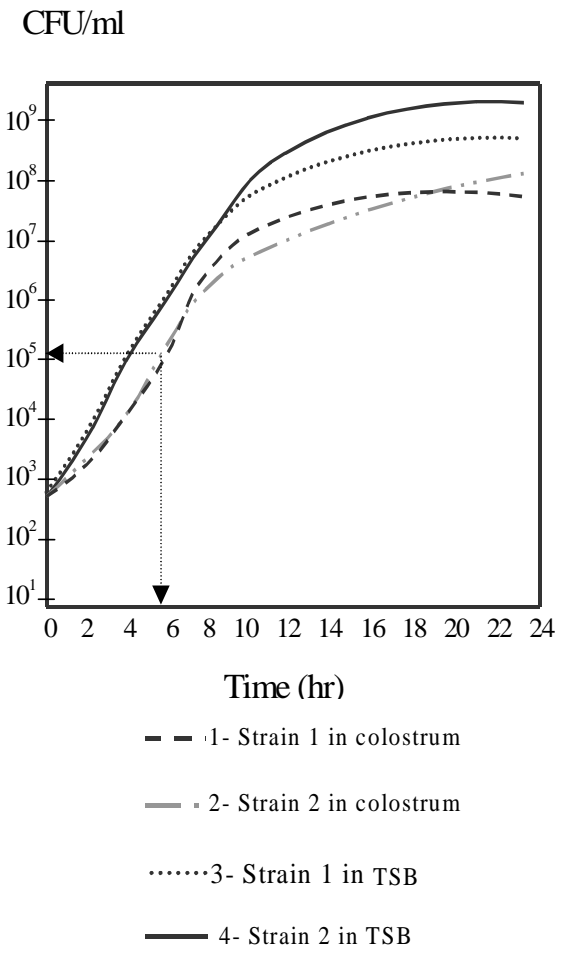

Fig. 3: growth of two EEB-producing Staphylococcus aureus strains in human colostrum and trypicase soy broth (TSB).

\section{DISCUSSION}

There was a high frequency of MRSA from $\mathrm{HM}$ and the mecA gene was present in all MRSA strains, as reported previously by De Lencastre et al. (1991). Concern over multiresistant, enterotoxin-producing $S$. aureus strains in hospital settings is justified by the report of Kluytmans et al. (1995), which described a MRSA hospital infection outbreak in Rotterdam, the Netherlands, transmitted through food prepared by a carrier with an MRSA isolate in these nostrils and oropharynx (Kluytmans et al. 1995). These reports indicate that healthy people may contribute to the dissemination of enterotoxin-producing MRSA clones, which produce and release toxins under conditions favoring growth. These toxins remain in contaminated food even after processing and the addition of antibiotics as preservatives.

In the present study, the fraction of MRSA that produced enterotoxin was much lower than that reported by other investigators working with clinical samples (Casman et al. 1967, Sourek et al. 1979, Melonian et al. 1983, Adesiyun et al. 1986, Humphreys 1989, Coia et al. 1992), and also lower than that reported by Pereira et al. (1995) for HM. However, those reports addressed enterotoxin-producing strains in the total $S$. aureus population present in the clinical samples. In contrast, we lim- 
ited our study to methicilin-resistant strains, and to samples unrelated to outbreaks of toxi-infection. On the other hand, a low occurrence of enterotoxin production in cow's milk was observed in a study of 201 strains, in which only one EEB-producing strain was detected, amounting to $0.5 \%$ of the total (Freitas \& Magalhães 1990).

According to Freitas and Magalhães (1990), enterotoxin-producing $S$. aureus strains are highly variable with regard to the frequency of isolation and to the type of enterotoxin produced. Pereira et al. (1991), in a study of intoxication induced by $S$. aureus in Belo Horizonte, Brazil, detected only production of EEB strains, and stressed the importance of such strains in Brazil (Pereira et al. 1991). Since, as proposed by Bohach et al. (1989), the gene for enterotoxin $\mathrm{B}$ is located on mobile genetic elements, which undergo integration into bacterial chromosomes (Bohach et al. 1989), it is possible that the presence of such elements accounts for the clonal diversity observed in EEB-producing strains (Soares et al. 1997). On the other hand, Renoud et al. (1994), studying 39 samples of EEBproducing $S$. aureus originating from clinical samples, classified them in three different clonal types, one of which was MRSA.

We believe the detection of toxins under our experimental conditions was mainly dependent on three factors: (a) the utilization of fresh culture, which may have rapidly adapted to the novel growth conditions; (b) the use of methodology able to detect $0.5 \mathrm{ng} / \mathrm{ml}$ which can detect enterotoxins even from poorly producing strains (Carmo \& Bergdoll 1990); and (c) absence of competitors (Mitsuoka 1992).

MRSA growth in human colostrum was slower than that observed in culture medium during the first $5 \mathrm{~h}$. This can probably be ascribed to antimicrobial factors associated to human colostrum, which include antistaphylococcal factor, lysozyme, macrophages and neutrophils (Wold \& Adlerberth 1998). Growth in colostrum was faster after $5 \mathrm{~h}$ possibly due to exhaustion of these factors but the cells did not reach the same final density as in culture media, which could be related to differences in access to nutrients under these different conditions (Brock et al. 1994).

The data reported here illustrate a hazard associated with storage of HM under inappropriate conditions, especially at hight environmental temperatures favoring growth of $S$. aureus. We suggest that implementation of stricter procedures for collection, processing, storage and distribution of $\mathrm{HM}$, especially in tropical regions, would help restrict contamination by $S$. aureus. Refrigeration or, preferably, freezing, is likely to be a good control measure, because if $S$. aureus grow at low tem- perature is not associated toxin release (Carmo \& Bergdoll 1990).

\section{REFERENCES}

Adesiyun AA, Raji I, Yobe V 1986. Enterotoxigenicity of Staphylococcus aureus from anterior nares of dining hall workers. J Food Protec 49: 955-957.

Almeida JAG, Novak FR, Almeida CHG 1998. Avaliação parcial da flora microbiana do leite humano ordenhado no IMIP. Revista do IMIP 3: 1316.

Bethey MJ, Harries TO 1994. Staphylococcal enterotoxins: genetic characterization and relationship between structure and emetic activity. Food Microbiol 11: 109-121.

Bohach GA, Kreiswirth BN, Novik RP, Schlievert PM 1989. Analysis of toxic shock syndrome isolates producing staphylococcal enterotoxin $B$ and $C_{1}$ with use of Southern hibridization and immunological assays. Rev Infect Dis (Suppl.) 11: 575-582.

Boyce JM, Jackson MM, Pugliese G, Batt MD, Fleming D, Garner JJS, Hartstein AI, Kauffman CA, Simmons M, Weinstein R, Williams CB 1994. Methicillin-resistant Staphylococcus aureus (MRSA): a briefing for acute care hospital and nursing facilities. Infect Control Hosp Epidemiol 15: 105-115.

Brasil-Ministério da Saúde 1998. Recomendações Técnicas para o Funcionamento de Bancos de Leite Humano, Brasília, 60 pp.

Brock TD, Modigan MT, Martinko JM, Parker J 1994. Biology of Microorganisms, 7th ed, Prentice Hall, New Jersey, 909 pp.

Carmo LS, Bergdoll MS 1990. Staphylococcal food poisoning in Belo Horizonte (Brasil). Rev Microbiol 21: 320-323.

Casman EP, Bennett RW, Dorsey AE, Issa JA 1967. Identification of a fourth Staphylococcal enterotoxin, enterotoxin D. J Bacteriol 94: 1875-1882.

Coia JE, Browning L, Haines L, Birkbek TH, Platt DJ 1992. Comparison of enterotoxins and haemolysins produced by methicillin-resistant (MRSA) and sensitive (MSSA) Staphylococcus aureus. J Med Microbiol 36: 164-171.

De Lancastre H, Figueiredo AMS, Urban C, Rahal J, Tomasz A 1991. Multiple mechanisms of methicillin resistance and imporved methods for detection in clinical isolates of Staphylococcus aureus. Antimicrob Agents Chemother 35: 632-639.

Embil J, Ramotar K, Romance L, Alfa M, Conly J, Cronk S, Taylor G, Sutherland B, Louiet T, Henderson E, Niolle LE 1994. Methicillin-resistant Staphylococcus aureus in tertiary care institutions on the canadian prairies 1990-1992. Infect Control Hosp Epidemiol 15: 646-651.

Freitas MAQ, Magalhães H 1990. Enterogenicidade de Staphylococcus aureus isolados de vacas com mastitite. Rev Microbiol 21: 315-319.

Humphreys H, Keone T, Hone R, Pomeroy H, Russell RJ, Arbuthnott JP, Coleman D 1989. Enterotoxin production by Staphylococcus aureus isolates from cases of septicoemia and healthy carriers. $J$ Med Microbiol 28: 163-172.

ICMSF-International Comission in Microbiological 
Specification for Food 1978. Microrganisms in Food. I. Their Significance and Methods of Enumeration, 2 ed., University of Toronto Press, Toronto, $434 \mathrm{pp}$.

Kloos WE, Bannerman TL. 1995. Staphylococcus and Micrococcus. In PR Murray, EJ Baron, MA Pfaller, FC Tenover \& RH Yolken (eds), Manual of Clinical Microbiology, Washington, p. 282-299.

Kluytmans J, Van Leeuwen W, Goessens W, Hollis R, Messer S, Herwoldt L, Bruining, H, Heck M, Rost J, Van Leeuwen N, Von Belkun A, Verbrugh H 1995. Food-initiated outbreak of methicillin-resistant Staphylocococcus aureus analyzed by pheno and genotyping. J Clin Microbiol 33: 1121-1128.

Layton MC, Hierholzer WJ, Patterson JE 1995. The evolving epidemiology of methicillin-resistant Staphylococcus aureus at a university hospital. Infect Control Hosp Epidemiol 16: 12-17.

Lebeau C, Vandenesh F, Greeniand T, Novik RP, Etienne J 1994. Coagulase expression in Staphylococcus aureus is positively and negatively modulated by an agr-dependent mechanism. J Bacteriol 176: 5534-36.

Machoshvili IA, Penna TCV, Colombo AJ 1991. Resistência térmica de cepas de Staphylococcus aureus em solução tampão fosfato (pH 7,0) e em leite reconstituído. Rev Microbiol 22: 323-329.

Melonian AK, Brun Y, Fleurette J 1983. Enterotoxin prodution, phage typing and serotyping of Staphylococcus aureus strains isolated from clinical materials and food. J Hyg Camb 91: 235-242.

Mitsuoka T 1992. Intestinal flora and aging. Nutrition Reviews 50: 438-346.

Nettleman MD, Trilla AA, Fredrikson M, Pfaller M 1991. Assigning responsibility: using feed bak to ahieve sustained control of methicillin-resitant Sta- phylococcus aureus. Am J Med 91 (Suppl. 3B): 228S$232 \mathrm{~S}$.

Pereira ML, Carmo LS, Santos EJ, Sellos IT, Bergdoll MS 1995. Staphylococci in breast milk from women with and without mastitis. Rev Microbiol 26: 117120.

Pereira ML, Lara MA, Dias RS, Carmo LS 1991. Intoxicação por Staphylococcus aureus provocado por queijo "tipo minas". Rev Microbiol 22: 349-350.

Renoud F, Bornstein N, Meugnier H, Forey F, Bes M, Fleurette J 1994. Clonal study of enterotoxin-B producing strains of Staphylococcus aureus. Epidemiol Infect 112: 501-516.

Soares MJS, Tokumaru-Miyazaki NH, Noleto ALS, Figueiredo AMS 1997. Enterotoxin production by Staphylococcus aureus clones detection of Brazilian epidemic MRSA clone (III::B:A) among isolates from food handlers workers. J Med Microbiol 46: 214-221.

Sourek J, Vymola F, Trajanova M, Zelenkova L, Matejovska V, Bergdoll MS 1979. Enterotoxin production by Staphylococcus aureus strains isolated from cases of chronic osteomyelitis. J Clin Microbiol 91: 266-268.

Speck ML 1996. Compendium of Methods for the Microbiological Examination of Foods, American Public Helath Association, Washington, New York, 807 pp.

Williams REO 1963. Healthy carriage of Staphylococcus aureus: its prevalence and importance. Bacteriol Rev 27: 56-71.

Wold AE, Adlerberth I 1998. Does bresatfeeding affect the infant's immune responsiveness? Acta Paediatr 87: 19-22. 